\title{
Prevalence of non-organ-specific autoantibodies and chronic liver disease in the general population: a nested case-control study of the Dionysos cohort
} M Lenzi, S Bellentani, G Saccoccio, P Muratori, F Masutti, L Muratori, F Cassani,
F B Bianchi, C Tiribelli

\begin{abstract}
Background-Several retrospective and prospective studies report an increased prevalence of non-organ-specific autoantibodies (NOSAs) in patients with hepatitis $\mathrm{C}$ virus (HCV) related chronic liver disease (CLD). Some of the data so far available are controversial and the true prevalence of NOSAs in the general population is still not known.
\end{abstract}

Aim-To explore the prevalence of NOSAs, their relation to different $\mathrm{HCV}$ genotypes, and the presence and severity of CLD in the general population of Northern Italy.

Patients-All 226 anti-HCV positive and 87 hepatitis B surface antigen (HBsAg) positive patients of the Dionysos cohort study were analysed and compared with sex and age matched cases (226) negative for both anti-HCV antibody and HBsAg selected from the same cohort.

Methods-Sera tested for the presence of NOSAs (anti-nuclear antibody (ANA), anti-smooth muscle antibody (SMA), and anti-liver/kidney microsomes type 1 antibody (LKM1)) were screened by indirect immunofluorescence at a 1:40 serum dilution. HCV RNA and HCV genotypes were also determined by nested polymerase chain reaction (PCR) of the $5^{\prime}$ non-coding region and by PCR amplification of the core region with type specific primers.

Results-The overall prevalence of NOSA reactivity was significantly higher in antiHCV positive subjects than in both normal and pathological controls $(25 \%$ v $6 \%$ and $7 \%$ respectively, $p<0.05)$. ANA, SMA, and LKM1 occurred in 16,10 , and $1.3 \%$ of cases respectively. No specific association between NOSAs and a specific HCV genotype was found. NOSAs were found more often associated with more than one genotype $(35.7 \%)$ and with untypable genotypes $(34.6 \%)$, although the association was not statistically significant. NOSAs were associated with HCV RNA and CLD but not with the presence of cirrhosis and/or hepatocellular carcinoma. On univariate analysis, NOSA reactivity was independently associated with abnormal alanine aminotransferase $(p<0.01)$ and $\gamma$-glutamyltranspeptidase levels $(p<0.05)$. The risk for the presence of NOSAs was
5.1 times higher in anti-HCV subjects than in controls.

Conclusions-In the general population the prevalence of NOSAs is higher in antiHCV positive subjects than in normal or disease controls. Moreover NOSAs are associated with CLD and with a more active disease in terms of alanine aminotransferase activity.

(Gut 1999;45:435-441)

Keywords: non-organ-specific autoantibodies; hepatitis C virus genotypes; chronic liver disease; cohort study; prevalence

The presence of immunological alterations are quite common in patients with chronic hepatitis $\mathrm{C}$ infection. The pattern of these immunological manifestations ranges from the simple presence of non-organ-specific autoantibodies (NOSAs) (anti-nuclear antibodies (ANA), anti-smooth muscle antibodies (SMA), and anti-liver/kidney microsomal type 1 antibodies (LKM1)), ${ }^{1-10}$ cryoglobulins, ${ }^{11-14}$ or anti-thyroid antibodies ${ }^{15}$ in the blood to immunological disease such as glomerulonephritis, ${ }^{16}$ lichen planus, ${ }^{17}$ lymphocytic sialadenitis, ${ }^{18}$ and mixed cryoglobulinaemia. ${ }^{12} 1920$ These associations may be interpreted as being the result of immune modulation induced by the lymphotropism of hepatitis C virus (HCV) itself ${ }^{21}$ or, as in the case of NOSAs, a manifestation secondary to the hepatocellular damage favoured by the genetic background of the host. ${ }^{22}$ The relation between NOSAs and HCV is based on epidemiological evidence; the clinical significance remains to be clarified. Nevertheless the interest of this association is supported by the observation of an exacerbation of the disease activity in patients positive for NOSAs during interferon treatment, suggesting the possibility that the immunomodulatory activity of the drug may activate an autoimmune reaction and the presence of

Abbreviations used in this paper: NOSA, non-organ-specific autoantibody; HCV, hepatitis $\mathrm{C}$ virus; CLD, chronic liver disease; HCC, hepatocellular carcinoma; HBsAg, hepatitis B surface antigen; IFL indirect immunofluorescence; ANA, anti-nuclear antibodies; SMA, anti-smooth muscle antibodies; LKM1, anti-liver/kidney microsomes type 1 antibodies; PCR, polymerase chain reaction; ELISA, enzyme linked immunosorbent assay; ALT, alanine aminotransferase; AST, aspartate aminotransferase; GGT, $\gamma$-glutamyltranspeptidase.
Accepted for publication 17 February 1999 
NOSAs is the hallmark of a subclinical autoimmune disease. ${ }^{23-25}$ Several studies have evaluated the prevalence of ANA and SMA in patients with $\mathrm{HCV}$ chronic infection as ranging between 6 and $21 \%$ and 14 and 55\% respectively. ${ }^{1-8}$ LKM1 are more rarely detected $(0-5 \%) .^{3-68-10}$ This wide range of prevalence reflects both the heterogeneous methodology used in the detection of NOSAs and/or different selection criteria of the patient population studied. No data are available on the prevalence of these markers in an unselected series of patients with HCV related chronic hepatitis.

The Dionysos study was the first cohort study to define the prevalence of chronic liver disease (CLD) in the general population of Northern Italy. We identified this study as an original model which could be used to address the controversial issue of the prevalence of NOSAs and their relation to CLD and HCV genotypes in an unselected series of patients. We therefore designed a nested case-control study inside the Dionysos cohort. ${ }^{26}$

\section{Materials and methods}

ENROLLMENT OF PATIENTS AND COMPLIANCE The details of the overall design of the Dionysos study have already been published. ${ }^{26}$ Briefly, all 10151 inhabitants between 12 and 65 years of age of two Northern Italian towns received a written invitation to participate in the study. Of these, 6917 were enrolled during the two years of the study. This number represents $69 \%$ of the eligible population - that is, a large enough fraction to validate this type of study. ${ }^{27}$

This paper analyses data relative to a nested case-control study performed inside the Dionysos cohort. All 226 individuals belonging to the Dionysos cohort found to be anti-HCV positive (second generation enzyme linked immunosorbent assay (ELISA)) during the first population screening, and followed up every six months for a period of three years were matched by age and sex with 226 subjects randomly selected in the group of subjects of the same study that were negative for anti-HCV, with the same proportion in the town of origin as observed in anti-HCV positive patients. All 87 patients found to be positive for hepatitis B surface antigen ( $\mathrm{HBsAg}$ ) in the same study were also chosen as another disease control group. Therefore, 539 subjects in total were analysed for the presence of NOSA reactivity.

INITIAL EVALUATION

The details of the overall design of the Dionysos study have been reported elsewhere. ${ }^{26}$ For each, the following was performed. (a) A medical history was obtained including family history of hepatitis in cohabiting people, presence of gallstone disease, history of past surgical operations, blood transfusions before 1990, drug abuse, dental procedures, dog or other domestic animal bites, homosexuality, acupuncture. The use of drugs was also registered. (b) A semiquantitative colour illustrated food questionnaire, including detailed questions on the use of alcoholic beverages (wine, beer, alcoholic aperitifs, hard liq- uor) and the dose, duration of use, and time of drinking, was administered. Daily alcohol intake (in $\mathrm{g}$ ) was computed by multiplying the frequency of consumption of each unit of beverage by the alcohol content of the specified portions..$^{27}$ (c) A detailed physical examination was carried out aimed at detecting physical signs related to CLD including height, weight, calculation of body mass index, left wrist circumference, presence of jaundice, scleral icterus, excoriation of skin, ascites, pretibial oedema, flapping tremor, spider naevi, palmar erythema, liver enlargement, palpable spleen. (d) A blood sample was taken for determination of alanine aminotransferase (ALT), aspartate aminotransferase (AST), and $\gamma$-glutamyltranspeptidase (GGT) activity, mean cell volume, platelet, erythrocyte, and leucocyte count, HBsAg, anti-HBs (Abbott Diagnostic Kits, North Chicago, Illinois, USA) and anti-HCV (ELISA, second generation; Ortho Diagnostic Kits, Raritan, New Jersey, USA). Each serum sample was divided under sterile conditions into three aliquots of $2 \mathrm{ml}$ and kept at $-80^{\circ} \mathrm{C}$ until used.

The diagnosis of cirrhosis was clinically suspected when at least two of the following features were present: $(a)$ spider naevi, scleral icterus, palmar erythema, ascites, flapping tremor, hepatic or splenic enlargement; (b) platelet count less than $140000 / \mathrm{mm}^{3}$; (c) portal vein diameter greater than $12 \mathrm{~mm}$ or irregular margins of the liver parenchyma at ultrasonography.

FOLLOW UP OF ANTI-HCV POSITIVE SUBJECTS

Each participant initially positive for anti-HCV (and confirmed to be positive by third generation ELISA and recombinant immunoblot assay (RIBA; Chiron Corp, Emeryville, California, USA)) and each subject for whom the diagnosis of cirrhosis was suspected clinically (see above) underwent the following additional procedures every six months for at least three years. (a) Baseline blood tests were repeated, and serum alkaline phosphatase, bilirubin, albumin, $\gamma$ globulin, prothrombin time, and $\alpha$ fetoprotein were also determined; blood assays of glucose, cholesterol, and triglycerides were also performed. (b) Ultrasonography of the liver, biliary system, pancreas, and spleen was performed, with measurement of portal vein and retropancreatic splenic vein diameters. All sonograms were performed by one operator.

\section{CLASSIFICATION OF CLD}

The diagnosis of cirrhosis and/or hepatocellular carcinoma (HCC) was suspected clinically according to the criteria reported above and confirmed by percutaneous liver biopsy in 36 subjects (27 anti-HCV positive, eight $\mathrm{HbsAg}$ positive, and one case-control with alcoholic cirrhosis). HCC was diagnosed in five antiHCV positive patients (four with cirrhosis). All the anti-HCV subjects with ALT more than 1.5 times the upper limit of normal in at least two measurements following one month interval checks were asked to undergo percutaneous liver biopsy. Of these, 55 met the criteria, and 53 had biopsies. Two patients with ALT more 
Table 1 Primers used for polymerase chain reaction amplification of the core region of hepatitis $C$ virus

\begin{tabular}{lll}
\hline Primer & Sequence (5'-3') & Nucleotide \\
\hline $\begin{array}{l}\text { Universal external } \\
\quad \text { Sense }\end{array}$ & CGCGCGACTAGGAAGACTTC & $139-158$ \\
$\quad$ Antisense & ATGTACCCCATGAGGTCGGC & $410-391$ \\
Internal & AGGAAGACTTCCGAGCGGTC & $148-167$ \\
$\quad$ Common sense & AggaAGACTTCCGAGCGGTC & $196-177(57 \mathrm{bp})$ \\
$\quad$ Type 1a & GAGCCATCCTGCCCACCCCA & $291-272(144 \mathrm{bp})$ \\
$\quad$ Type 1b & CCAAGAGGGACGGGAACCTC & $321-302(174 \mathrm{bp})$ \\
$\quad$ Type 2a & ACCCTCGTTTCCGTACAGAG & $270-251(123 \mathrm{bp})$ \\
Type 2b $3 \mathrm{a}$ specific & CGCGCGACGCGTAAAACTTC & $139-158$ \\
$\quad$ External sense & CGTAAAACTTCTGAACGGTC & $148-167$ \\
Internal sense & GCTGAGCCCAGGACCGGTCT & $235-214$ \\
\hline
\end{tabular}

than 1.5 times the upper limit of normal, but without clinically suspected cirrhosis, declined to have a biopsy.

Finally, all 539 subjects of this nested case-control study underwent two consecutive one month interval checks of ALT and GGT during the last year of follow up. When the diagnosis of cirrhosis and/or HCC was reached (see above) and when either ALT or GGT were above the upper normal range, the subject was considered to have CLD.

VIROLOGICAL STUDIES

Anti-HCV antibodies were tested by the second generation immunoenzymatic screening test ORTHO-HCV (Ortho diagnostic Kits) and confirmed by recombinant immunoblot assay when positive. Serum HCV RNA was tested by "nested" PCR using primers for 5'untranslated region. This test was performed in all subjects positive for anti-HCV in the serum sample at presentation, and, in the case of a negative result, the test was repeated in serum samples collected during the follow up.

HCV genotypes were determined by PCR amplification of the core region as described by Okamoto and co-workers. ${ }^{28}$ Each HCV type was characterised by a different nucleotide length: 49 for type 1a, 144 for type 1b, 174 for type $2 \mathrm{a}$, and 123 for type $2 \mathrm{~b}$. When a double infection was suspected because of the presence of several bands, a second PCR was separately repeated with each of four type-specific antisense primers. Table 1 gives the primers used. As an additional type (3a) of $\mathrm{HCV}$ has been recently described, the above method was slightly modified by using primers able to detect type $3 \mathrm{a}$ of HCV. A sense primer was added in the first PCR and a new pair of primers in the second PCR (table 1). Using these primers, a specific 88 bp long product could be obtained.

AUTOANTIBODY TESTING

ANA, SMA, LKM1, and anti-mitochondrial antibodies were searched for by indirect immunofluorescence (IFL) on cryostat sections of rat liver and kidney at a serum dilution of 1:40 as suggested by Johnson et al. ${ }^{29}$ Positive reactions were titred by double dilution to the end point. ANA positive sera were subsequently tested at the same dilution by IFL on HEp-2 cells (Kallestad, Chaska, Minnesota, USA); homogeneous and other ANA patterns were identified according to established criteria. $^{30}$ Anti-double-stranded DNA was tested by IFL on Crithidia luciliae.

Anti-extractable nuclear antigen (ENA) reactivities and $X R_{1}$ precipitin system were tested by counterimmunoelectrophoresis with rabbit thymus extract (Pel-Freez, Rogers, Arkansas, USA).

Anti-actin specificity was identified on the basis of a SMAg (staining of the vessel walls plus glomerular mesangium) or SMAt pattern (all the above plus staining of filamentous peritubular structures) by IFL on kidney sections as described by Bottazzo et $a l^{\beta 1}$ and by positivity for the XR1 precipitating system by counterimmunoelectrophoresis with rabbit thymus extract. The XR1 precipitin line is immunologically distinct from each of the most common ENA systems (Sm, NRNP, SS-A, SS-B, Jo-1, and Scl-70) which are routinely detected using the same technical procedure. The above reactivities have been shown to be closely associated with anti-actin reactivity. ${ }^{32}$

LKM1 and anti-mitochondrial antibody reactivities were further evaluated by immunoblotting on rat liver microsomes and bovine heart mitochondrial preparations respectively, at a serum dilution of 1:500.

STATISTICAL ANALYSIS

Statistical analysis was performed with an SPSS/PC statistical package (SPSS Inc, Chicago, Illinois, USA). All $\mathrm{p}$ values reported are two-tailed. Statistical comparison between means was calculated by one way analysis of variance, and, when the variances were not homogeneous, with the Kruskal-Wallis one way analysis of variance. ${ }^{33}$

The association between the presence of NOSA positivity and different variables (antiHCV positivity, HCV RNA positivity, different HCV genotypes; the persistent presence of either ALT activity higher than $40 \mathrm{U} / 1$ or GGT activity higher than $50 \mathrm{U} / 1$; the presence of CLD as defined above and the presence of cirrhosis/HCC) were assessed with the univariate unadjusted $\chi^{2}$ statistic. ${ }^{34}$ Odds ratios and $95 \%$ confidence intervals were also calculated. ${ }^{35}$ The multivariate analysis was carried out by a linear logistic regression model, ${ }^{36}$ with a stepwise variable selection procedure (level for entry $=0.1$, level for stay $=0.5)$. The models explain either the probability of NOSA positivity according to the different $\mathrm{HCV}$ genotypes or the probability of NOSA positivity according to the presence of CLD or cirrhosis/HCC in the nested case-control population studied $(n=539)$. Independently from the selection criteria used, age and daily alcohol intake (in g/day) were always considered in the multivariate analysis in order to improve model fitting.

\section{Results}

Table 2 reports the demographic, clinical, and biochemical features of the population studied at baseline as well as those of the control groups. The mean (SD) age of the anti-HCV positive patients and case-controls was 52 (12) years. HbsAg positive patients were all $\mathrm{HBV}$ 
Table 2 Demographic, clinical and biochemical features of the population studied

\begin{tabular}{llll}
\hline & $\begin{array}{l}\text { Anti-HCV positive } \\
(n=226)\end{array}$ & $\begin{array}{l}\text { Case controls } \\
(n=226)\end{array}$ & $\begin{array}{l}\text { HbsAg positive } \\
(n=87)\end{array}$ \\
\hline Sex (M/F) & $95 / 131$ & $95 / 131$ & $55 / 32$ \\
Mean (SD) age (years) & $52(12)$ & $52(12)$ & $43(11)^{\star}$ \\
Alcohol intake (g/day) (mean & $24.6(2.8)$ & $23.7(2.3)$ & $25.0(3.6)$ \\
$\quad(\mathrm{SE}))$ & $119 ; 52.7^{\star}$ & $44 ; 19.2$ & $28 ; 32.2$ \\
CLD (n; \%) & $27 ; 11.9$ & $1 ; 0.4 \dagger$ & $8 ; 9.2$ \\
$\quad$ With cirrhosis (n; \%) & $4.3(0.4)$ & $4.4(0.2)$ & $4.5(0.4)$ \\
Albumin (g/l) (mean (SD)) & $1.5(0.4)$ & $1.2(0.2)$ & $1.3(0.3)$ \\
$\gamma$-Globulins (g/l) (mean (SD)) & $48(4)$ & $24(1)$ & $34(4)$ \\
ALT (mean (SE)) & $39(3)$ & $30(2)$ & $42(12)$ \\
GGT (mean (SE)) & & & \\
\hline
\end{tabular}

${ }^{\star} \mathrm{p}<0.05 v$ other groups.

†Man with alcoholic cirrhosis.

CLD, chronic liver disease; ALT, alanine amonitransferase; GGT, $\gamma$-glytamyltranspeptidase.

DNA negative except one, with a slight prevalence of men and a mean age of 43 (11). ALT and $\gamma$-globulin levels were significantly higher and a diagnosis of CLD significantly more common in anti-HCV positive patients than in case-controls and HBsAg positive patients $(\mathrm{p}<0.05)$.

Table 3 gives the overall prevalence of NOSAs in the population studied and control groups. Autoantibodies were found in 57/226 $(25 \%)$ subjects positive for anti-HCV with a median titre of $1: 40$ (range $1: 40-1: 1280$ ), in $6 / 87(7 \%)$ subjects positive for $\mathrm{HBsAg}$, and in $14 / 226(6 \%)$ healthy controls (median titre $1: 40$; range $40-320)$. The prevalence was significantly higher in the former than in the two latter groups $(p<0.05)$. ANA reactivity was more often observed $(36 / 226 ; 16 \%)$ in anti$\mathrm{HCV}$ positive than in control groups $(8 / 226$ $(3.5 \%)$ and $2 / 87(2.3 \%)$ respectively). The homogeneous pattern on HEp-2 cells was observed in $3 / 36(8 \%)$ anti-HCV positive cases (titres $1: 40,1: 80$, and $1: 160$ respectively) and in $1 / 14(7 \%)$ case-controls (titre $1: 80)$. None of the ANA positive sera were positive for anti-double-stranded DNA or anti-ENA. SMA reactivity was found in $22 / 226(10 \%)$ antiHCV positive patients and 6/226 (2.6\%) and $4 / 87(4.6 \%)$ case-controls and disease controls respectively. The SMAg and SMAt IFL pattern was present in two anti-HCV positive patients and in one control. None of the SMA positive sera showed XR1 precipitating reactivity, indicating an anti-actin specificity. The concomitant reactivity for ANA and SMA was shown only in $5 / 226(2.2 \%)$ anti-HCV subjects

Table 3 Prevalence (expressed as column percentage in the table) of different non-organ-specific autoantibodies (NOSAs) within the population studied in relation to the presence of chronic liver disease (CLD)

\begin{tabular}{llll}
\hline & $\begin{array}{l}\text { Anti-HCV positive } \\
(n=226)\end{array}$ & $\begin{array}{l}\text { Case controls } \\
(n=226)\end{array}$ & $\begin{array}{l}\text { HbsAg positive } \\
(n=87)\end{array}$ \\
\hline NOSA positive (total) & $57(25)^{\star}$ & $14(6)$ & $6(7)$ \\
With CLD & $31(14)^{\star}$ & $4(1.8)$ & $2(2.3)$ \\
ANA positive (total) & $36(16)^{\star}$ & $8(3.5)$ & $2(2.3)$ \\
With CLD (1. & $14(6.2)^{\star}$ & $3(1.3)$ & $1(1.1)$ \\
SMA positive (total) & $22(10)^{\star}$ & $6(2.6)$ & $4(4.6)$ \\
With CLD & $11(5)^{\star}$ & $1(0.4)$ & $1(1.1)$ \\
LKM1 positive (total) & $3(1.3)^{\star}$ & $0(0)$ & $0(0)$ \\
With CLD & $3(1.3)^{\star}$ & $0(0)$ & $0(0)$ \\
ANA + SMA positive (total) & $5(2.2)^{\star}$ & $0(0)$ & $0(0)$ \\
With CLD & $0(0)$ & $0(0)$ & $0(0)$ \\
AMA positive (total) & $1(0.4)^{\star}$ & $0(0)$ & $0(0)$ \\
With CLD & $1(0.4)^{\star}$ & $0(0)$ & \\
\hline
\end{tabular}

Values in parentheses are percentages.

${ }^{\star} \mathrm{p}<0.05 v$ other groups.

ANA, anti-nuclear antibodies; SMA, anti-smooth muscle antibodies; LKM, anti-liver/kidney microsomes type 1 antibodies; AMA, anti-mitochondrial antibodies. (median titre 1:80; range 1:40-1:160) and never in the control groups. The prevalence of NOSAs was significantly higher in patients with CLD $(p<0.05)$. LKM1 reactivity was found only in three anti-HCV positive cases $(1.3 \%)$ with a titre of $1: 80$ in one serum sample and 1:1280 in the remaining two. These three sera all reacted in immunoblots with a $50 \mathrm{kDa}$ rat liver microsomal peptide. One serum sample from an anti-HCV positive female patient with CLD was positive by IFL for antimitochondrial antibody with a titre of 1:1280. When tested by immunoblotting on bovine heart mitochondria, the above serum sample showed a reactivity against 74,52 , and $51 \mathrm{kDa}$ peptides typical for M2 specificity.

Table 4 reports the prevalence of NOSAs within the different classes of HCV genotype. No specific association between NOSAs and a specific HCV genotype was found. Interestingly, higher NOSA prevalence was found in HCV RNA positive patients infected with two or more genotypes $(35.7 \%)$ or with untypable genotypes (34.6\%). LKM1 was found in association with $\mathrm{HCV}$ genotype $1 \mathrm{~b}$ in two cases and with untypable genotypes in the third.

Anti-HCV positive patients and casecontrols, with the exclusion of $\mathrm{Hbs} \mathrm{Ag}$ positive patients, were compared by different variables using univariate analysis. The results showed an association between serum autoantibody positivity and both anti-HCV or HCV RNA positivity and the presence of CLD $(p<0.001$, $p<0.05$ and $p<0.05$ respectively), but not with the presence of cirrhosis and/or HCC (table 5). With regard to the biochemical variables, NOSA reactivity was shown to be independently associated with abnormal levels of ALT $(p<0.001)$ and GGT $(p<0.05)$. Analysing the NOSA specificity, ALT alteration was associated also with SMA reactivity $(\mathrm{p}<0.05)$, and GGT with ANA $(\mathrm{p}<0.05)$. Moreover, the risk of cirrhosis and/or HCC was 3.8 times higher (range 1-14.1, p<0.05) when both SMA positivity and genotype $1 \mathrm{~b}$ were present. No significant differences were found between HBsAg positive patients and case-controls. Finally, the overall risk for the presence of autoantibodies was 5.1 times higher (range 2.8-9.6) in anti-HCV positive subjects than in case-controls $(p<0.05)$ and it was similar for ANA and SMA specificities (odds ratio $=5.2$ (range 2.4-11.5) and 4 (range 1.6-10.1) respectively).

Multivariate analysis of the data, after correction for age and daily alcohol intake, showed that none of the NOSA specificity was significantly associated with the presence of either CLD or cirrhosis/HCC. The NOSA specificity that was closest to statistical significance for the presence of cirrhosis/HCC was LKM1 reactivity ( $\mathrm{p}=0.150$; data not shown). When the probability of NOSA positivity according to HCV genotype was explored by multiple logistic regression, after correction for age and daily alcohol intake, NOSA positivity was found to be significantly correlated ( $\mathrm{p}=$ 0.0007 ) with the presence of two or three genotypes, with the presence of an "untypable" 
Table 4 Prevalence and titre of non-organ-specific autoantibodies (NOSA) within the different classes of hepatitic $C$ virus (HCV) genotypes

\begin{tabular}{lllllll}
\hline & ANA & SMA & ANA + SMA & LKM1 & AMA & Total NOSA \\
\hline HCV RNA positive & $18^{\star}(11.1)$ & $13^{\star}(8.0)$ & $3(1.8)$ & $3(1.8)$ & $1(0.6)$ & $38^{\star}(23.5)$ \\
Genotype 1a (n=7) & $0(0)$ & $1(14.3)$ & $0(0)$ & $0(0)$ & $0(0)$ & $1(14.3)$ \\
Genotype 1b (n=68) & $4(5.9)$ & $7(10.3)$ & $1(1.5)$ & $2(2.9)$ & $1(1.5)$ & $15(22)$ \\
Genotype 2a (n=39) & $4(10.3)$ & $2(5.1)$ & $0(0)$ & $0(0)$ & $0(0)$ & $6(15.4)$ \\
Genotype 2b (n=1) & $1(100)$ & $0(0)$ & $0(0)$ & $0(0)$ & $0(0)$ & $1(100)$ \\
Genotype 2c (n=4) & $0(0)$ & $0(0)$ & $1(25)$ & $0(0)$ & $0(0)$ & $1(25)$ \\
Genotype 3a (n=3) & $0(0)$ & $0(0)$ & $0(0)$ & $0(0)$ & $0(0)$ & $0(0)$ \\
Genotype untypable (n=26) & $5(19)$ & $2(7.7)$ & $1(3.8)$ & $1(3.8)$ & $0(0)$ & $9(34.6)$ \\
Two or three genotypes (n=14) & $4(36.4)$ & $1(9.1)$ & $0(0)$ & $0(0)$ & $0(0)$ & $5(35.7)$ \\
\hline
\end{tabular}

Values in parentheses are percentages.

${ }^{\star} \mathrm{p}<0.05 v$ other groups.

ANA, anti-nuclear antibodies; SMA, anti-smooth muscle antibodies; LKM1, anti-liver/kidney microsomes type 1 antibodies; AMA, anti-mitochondrial antibodies.

Table 5 Univariate analysis of alterations in alanine aminotransferase (ALT) and $\gamma$-glutamyltranspeptidase (GGT), and the presence of chronic liver disease (CLD) and cirrhosis for non-organ-specific autoantibody (NOSA) reactivity in the population of anti-hepatitis $C$ virus $(H C V)$ positive subjects $(n=226)$ and their matched case controls $(n=226)$. Hbs $A g$ positive subjects were excluded from the analysis. Absolute number ( $n)$, percentage of row (\%) and odds ratio (OR) with $95 \%$ confidential intervals (CI) are also reported

\begin{tabular}{|c|c|c|c|c|c|c|}
\hline \multirow[b]{2}{*}{ Factor } & \multicolumn{2}{|c|}{ NOSA postitive } & \multicolumn{2}{|c|}{ ANA positive } & \multicolumn{2}{|c|}{ SMA positive } \\
\hline & $n(\%)$ & OR $(95 \% C I)$ & $n(\%)$ & OR $(95 \% C I)$ & $n(\%)$ & OR $(95 \% C I)$ \\
\hline $\mathrm{ALT}>40 \mathrm{IU} / 1$ & & $1.5(1.0 \text { to } 2.7)^{\star}$ & & $0.8(0.3 \text { to } 1.8)^{\star}$ & & $2.5(1.1 \text { to } 5.6)^{\star}$ \\
\hline Present $(n=98)$ & $20(20)$ & & $8(8.2)$ & & $11(11.2)$ & \\
\hline Absent $(n=354)$ & $51(14.4)$ & & $36(10.2)$ & & $17(4.8)$ & \\
\hline $\mathrm{GGT}>50 \mathrm{IU} / 1$ & & $2.9(1.6 \text { to } 5.0)^{\star \star}$ & & $2.5(1.2 \text { to } 4.8)^{\star \star}$ & & $1.8(0.8$ to 4.2$)$ \\
\hline Present $(n=86)$ & $25(29)$ & & $15(17)$ & & $8(9)$ & \\
\hline Absent $(n=366)$ & $46(12.6)$ & & $29(8)$ & & $20(5.5)$ & \\
\hline CLD & & $2.0(1.7 \text { to } 2.3)^{\star}$ & & $1.3(0.7$ to 2.6$)$ & & $1.7(0.8$ to 4.0$)$ \\
\hline Present $(n=154)$ & $37(24)$ & & $18(11.5)$ & & $13(8)$ & \\
\hline Absent $(n=298)$ & $40(13.4)$ & & $28(9.4)$ & & $19(6.4)$ & \\
\hline Cirrhosis/HCC & & $1.9(0.8$ to 4.6$)$ & & $1.1(0.3$ to 3.9$)$ & & $1.9(0.5$ to 6.8$)$ \\
\hline Present $(n=28)$ & $7(25)$ & & $3(11)$ & & $3(11)$ & \\
\hline Absent $(n=424)$ & $64(15.1)$ & & $41(10)$ & & $25(5.9)$ & \\
\hline
\end{tabular}

${ }^{\star} \mathrm{p}<0.05,{ }^{\star \star} \mathrm{p}<0.01$.

HCC, hepatocellular carcinoma.

genotype $(p=0.0007)$, and with the presence of genotype $1 b(\mathrm{p}=0.006)$.

\section{Discussion}

The true prevalence of CLD and cirrhosis and its clinical and biochemical characteristics in most of the studies published reflects the selection criteria used in each study. The Dionysos cohort study evaluates, for the first time, the prevalence and incidence of CLD in the general population of Northern Italy. A sample of 6917 citizens, aged 12 to 65, from two towns characterised by the same socioeconomic background was analysed. From the data obtained in this study, the prevalence of hepatitis $B$ virus and $\mathrm{HCV}$ positivity was 1.3 and $3.2 \%$ respectively. The overall prevalence of HCV RNA positive patients was $2.3 \%$. The anti-HCV positive cohort members were deemed to be the ideal series of patients in which to evaluate the prevalence of NOSAs associated with $\mathrm{HCV}$ infection, in a general population, and their correlation with CLD and biochemical variables of liver disease activity. We regarded them as an ideal cohort given the absence of selection bias that characterises the retrospective and prospective studies already published.

There is a general consensus that serum autoantibodies are commonly found in patients with hepatitis C (about one third of all cases). The overall prevalence of NOSAs found in this study $(25 \%)$ is only slightly lower than that observed in previous reports from Europe 2369 and the United States in which the same screening dilution (1:40) (as recommended in adults) was used. ${ }^{45810}$ This also confirms that, in an unselected population, this phenomenon is specifically associated with HCV infection. The prevalence of NOSAs in our disease control group (HbsAg positive patients) is very low compared with those reported in the literature ${ }^{4536}$; this probably reflects the fact that most of our patients were in a nonreplicative state and had inactive liver disease. We observed a higher prevalence of ANA $(16 \%)$ than SMA positivity $(10 \%)$, in contrast with some previous reports, ${ }^{4-6}$ but in accordance with the results of Czaja et al. ${ }^{36}$ There is no obvious explanation for this finding, but interestingly the same relation between the two reactivities is also present in the case-controls group. LKM1 was found only in anti-HCV/ HCV RNA positive patients with a prevalence of $1.3 \%$. This confirms the specific association between this rare autoantibody and $\mathrm{HCV}$ infection. The prevalence of LKM1 found in this study is significantly lower than that observed in most European studies. ${ }^{1-3936}$ This result can be explained by assuming that in most European studies there is a selection bias for LKM1 positive patients, possibly because of the long term interest in this antibody on the part of certain authors. The prevalence of LKM1 is in fact similar to that reported in certain American studies. ${ }^{510}$ This would suggest that the association of this autoantibody and HCV infection is geographically independent. From this we would also infer that the difference in the prevalence of LKM1 in HCV 
infected patients reported in American and European cohorts is selection based.

The analysis of ANA and SMA subspecificities shows that most of the autoantibodies detected in this study were ANA with a speckled pattern, and SMA were directed against cytoskeletal proteins (intermediate filaments) other than actin. Only $3 / 36(8 \%)$ of the anti-HCV positive subjects showed an ANA with a homogeneous pattern similar to that usually associated with autoimmune hepatitis, while anti-actin specificity was never detected. Therefore the overlap between autoimmune and viral hepatitis in terms of autoantibody specificities is very low in this study and confirms that ANA with a homogeneous pattern is less specific than anti-actin for the diagnosis of autoimmune hepatitis, as it has been detected in few cases of anti-HCV positive and control cases $(1 / 14 ; 7 \%)$. Comparing the results obtained in this study with those reported by Cassani et al in both a retrospective $^{2}$ and prospective ${ }^{37}$ series of antiHCV positive patients, we observe that, although the overall prevalence of NOSAs is similar in the two studies, the prevalence of the subspecificities of homogeneous ANA and SMA with anti-actin is significantly lower. This difference can be explained in the light of the patients studied and suggests that, in unselected patients, the overlap between chronic hepatitis C with autoimmune features and autoimmune hepatitis is very low both in terms of autoantibody specificity and titre. Moreover, these findings indicate that most of the autoimmune reactions that often occur in association with $\mathrm{HCV}$ infection are those typically described in various viral disorders, ${ }^{38-40}$ probably favoured by the protracted stimulation of the immune system by a direct effect of $\mathrm{HCV}$ on lymphocytes and on the basis of a particular genetic background of the host.

The association between the presence of NOSAs and the clinical, biochemical, and histological picture of $\mathrm{HCV}$ related CLD is still controversial. Several reports have failed to identify the presence of NOSAs as an untoward factor for CLD. The study of Cassani et $a l^{37}$ showed for the first time, in a prospective series of patients with HCV related CLD who were positive for autoantibodies, a biochemical and histological activity higher than that of patients with no markers of autoimmunity. These results are strengthened by the observations obtained in this study confirming in unselected patients that the presence of NOSAs is significantly associated with the presence of CLD, with $\mathrm{HCV}$ infection in a replicative state (presence of HCV RNA), and with higher levels of ALT and GGT. More specifically a link between the presence of reactivity for SMA and HCV genotype $1 \mathrm{~b}$ and cirrhosis has also been shown. These data are insufficient to prove a direct relation between NOSAs and the progression of liver damage. In fact, a hypothetical immune mechanism of liver damage is still unproven, and "viral autoimmunity" has so far been considered to be a simple consequence of the severity of liver damage without any active role. However, the cumulative data that associate NOSAs with the progression of liver disease indicate that their evaluation is important, at least as a marker of liver disease activity during $\mathrm{HCV}$ infection. Further investigation is required to understand their significance better.

In conclusion, evaluation of autoimmune phenomena associated with HCV infection, in an unselected Northern Italian population, has confirmed that NOSAs are commonly associated with HCV infection. The overall specificities of these autoantibodies account for the autoimmunity associated with viral infections, and the overlap with autoimmune hepatitis is negligible. Interestingly, they correlate with the activity of liver disease, suggesting a hypothetical role in the progression of liver damage.

1 Lenzi M, Johnson PJ, McFarlane IG, et al. Antibodies to hepatitis $\mathrm{C}$ virus in autoimmune liver disease: evidence for geographical heterogeneity. Lancet 1991;338:277-80.

2 Cassani F, Muratori L, Manotti P, et al. Serum autoantibodies and the diagnosis of type-1 autoimmune hepatitis in Italy: a reappraisal at the light of hepatitis $\mathrm{C}$ virus infection. Gut 1993;33:1260-3.

3 Abuaf N, Lunel F, Giral P, et al. Non-organ specific autoantibodies associated with chronic $\mathrm{C}$ virus hepatitis. $\mathcal{F}$ Hepatol 1993;18:359-64.

4 Fried MW, Draguesku JO, Shindo M, et al. Clinical and serological differentiation of autoimmune and hepatitis C

Clifford BD, Donahue D, Smith L, et al. High prevalence of serological markers of autoimmunity in patients with chronic hepatitis C. Hepatology 1995;21:613-19.

6 Meyer zum Buschenfelde KH, Lohse AW, Gerken G, et al. Meyer zum Buschenfelde $\mathrm{KH}$, Lohse AW, Gerken G, et al.
The role of autoimmunity in hepatitis $\mathrm{C}$ infection. F Hepatol 1995;22 (suppl 1):93-6.

7 Czaja AJ, Carpenter HA, Santrach PJ, et al. Evidence aganst hepatitis viruses as inportant causes of severe autoimmune hepatitis in the united States. F Hepatol 1993;18:342-52.

8 Reddy KR, Krawitt EL, Homberg JC, et al. Absence of LKM1 antibody in hepatitis C viral infection in the United States. F Viral Hepat 1995;2:175-9.

9 Lunel F, Abuaf N, Frangeul L, et al. Liver/kidney microsome antibody type 1 and hepatitis $\mathrm{C}$ virus infection. Hepatology 1992;16:630-6.

10 Czaja, AJ, Manns MP, Homburger HA. Frequency and significance of antibodies to liver/kidney microsome type 1 in adult with cronic hepatitis. Gastroenterology 1992;103. 1290-5.

11 Ferri C, Greco F, Longobardo G, et al. Antibodies to hepatitis C virus in patients with mixed cryoglobulinemia. Arthritis Rheum 1991;34:1606-10.

12 Lunel F, Musset L, Franjeul L, et al. Cryoglobulinemia in chronic liver diseases: role of hepatitis $\mathrm{C}$ virus and liver damage. Gastroenterology 1994;106:1291-300.

13 Cacoub P, Lunel-Fabiani F, Musset L, et al. Mixed cryoglobulinemia and hepatitis $\mathrm{C}$ virus. $\mathrm{Am}$ f $\mathrm{Med}$ 1994;96:124-32.

14 Agnello V, Chung RT, Kaplan LM. A role for hepatitis C virus infection in type II cryoglobulinemia. $N$ Engl $\mathcal{F}$ Med 1992;327:1490-5

15 Tran A, Quaranta JF, Benzaken S, et al. High prevalence of thyroid autoantibodies in a prospective series of patients with chronic hepatitis $\mathrm{C}$ before interferon therapy. Hepatology 1993;18:253-7.

16 Johnson JR, Gretch DR, Yamabe H, et al. Menbranoprolifrative glomerulonephritis associated with hepatitis $\mathrm{C}$ virus infection. N Engl f Med 1993;328:465-70.

17 Pawlotsky JM, Ben Hayia M, Andrè C, et al. Immunological disorders in $\mathrm{C}$ virus chronic active hepatitis: a prospective case-control study. Hepatology 1994;19:841-8.

18 Haddad J, Deny P, Munz-Gotheil C, et al. Lymphocytic sialoadenitis of Sjogren's syndrome associated with chronic hepatitis C virus liver disease. Lancet 1992;339:321-3.

19 Adinolf LE, Utili R, Attanasio V, et al. Epidemiology, clinical spectrum and prognostic value of mixed cryoglobulinemia in hepatitis $C$ virus patients: a prospective study. Ital $f$ Gastroenterol 1996;28:1-9.

20 Wong VS, Egner W, Elsey T, et al. Incidence, character and clinical relevance of mixed cryoglobulinemia in patients with chronic hepatitis C virus infection. Clin Exp Immunol 1996;104:25-31.

21 Muratori L, Gibellini D, Lenzi M, et al. Quantification of hepatitis C virus-infected peripheral blood mononuclear cells by in situ reverse transcriptase-polymerase chain reaction. Blood 1997;88:2768-74.

22 Czaja AJ, Herschel A, Carpenter A, et al. Immunological features and HLA association in chronic viral hepatitis. Gastroenterology 1995;108:157-64.

23 Ruiz-Moreno M, Rua MJ, Carreno V, et al. Autoimmune chronic hepatitis type 2 manifested during interferon therapy in children. F Hepatol 1991;12:265-6. 
24 Papo T, Marcellin P, Bernuau J, et al. Autoimmune chronic hepatitis exacerbated by alpha-interferon. Ann Intern Med hepatitis exacerb

25 Muratori L, Lenzi M, Cataleta $M$, et al. Interferon therapy in liver/kidney microsomal antibidy type 1-positive patient with chronic hepatitis C. $\mathcal{F}$ Hepatol 1994;21:199-203.

26 Bellentani S, Tiribelli C, Saccoccio G, et al. Prevalence of chronic liver disease in the general population of northern Italy: the Dionysos study. Hepatology 1994;20:1442-9.

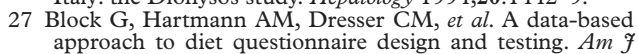
Epidemiol 1986;124:453-69.

28 Okamoto H, Sugiyama Y, Okada S, et al. Typing hepatitis C virus by polymerase chain reaction with type specific primers: application to clinical surveys and tracing infection sources. f Gen Virol 1992;73:673-9.

29 Johnson PJ, McFarlane IG (convenors on behalf of the panel). Meeting report: International Autoimmune Hepatipanel). Meeting report: International Auto

30 Cassani F, Bianchi FB, Lenzi M, et al. Immunomorphological characterization of antinuclear antibodies in chronic cal characterization of antinuclear antiboditin
liver disease. 7 Clin Pathol 1985;38:801-5.

31 Bottazzo GF, Florin-Christensen A, Fairfax A, et al. Classification of smooth muscle autoantibodies (SMA) detected by immunofluorescence. F Clin Pathol 1976;29:403-10.

32 Cassani F, Fusconi M, Bianchi FB, et al. Precipitating antibodies to rabbit thymus extractable antigens in chronic liver disease: relationship with anti-actin antibodies. Clin Exp Immunol 1987;68:588-95.

33 Meier P, Beach M. Biostatistics for the clinician. In: Chalmers TC, ed. Data analysis for clinical medicine. Rome: International University Press, 1988:7-29.

34 Fleiss JL. Statistical methods for rates and proportions. New York: Wiley and Sons, 1981:83-99.

35 Hosmer DW Jr, Lemeshow S. Applied logistic regression. New York: John Wiley, 1989.

36 Czaja AJ, Carpenter HA, Santrach PJ, et al. Immunologic features and HLA association in chronic viral hepatitis. Gastroenterology 1995;108:157-64.

37 Cassani F, Cataleta M, Valentini P, et al. Serum autoantibodies in chronic hepatitis C: comparison with autoimmune hepatitis and impact on the disease profile. Hepatology 1997;26:561-6.

38 Holborow EJ, Hemsted EH, Mead SV. Smooth muscle autoantibodies in infectious mononucleosis. BMF 1973;3: 323-5.

39 Pedersen JS, Toh BH, Mackay IR, et al. Segregation of autoantibody to cytoskeletal filaments, actin and intermediate filaments with two types of chronic active hepatitis. Clin Exp Immunol 1982;48:527-32.

40 Cassani F, Tremolada F, Baffoni L, et al. Markers of "viral" autoimmunity in chronic non-A, non-B post-transfusion hepatitis. Ital f Gastroenterol 1988;20:171-4. 